\title{
Impacts of Fracture Roughness and Near-wellbore Tortuous on Proppant Transport Within Hydraulic Fractures
}

\section{Di Wang}

State Key Laboratory of Shale Oil and Gas Enrichment Mechanisms and Effective Development, Beijing, 100083, China

\section{Bingyang Bai}

China University of Petroleum, Beijing

\section{Bin Wang}

China University of Petroleum, Beijing

\section{Dongya Wei}

China University of Petroleum, Beijing

Tianbo Liang ( $\sim$ liangtianboo@163.com )

China University of Petroleum, Beijing

\section{Research Article}

Keywords: Proppant transport, Fractures roughness, Tortuous fractures

Posted Date: December 14th, 2021

DOI: https://doi.org/10.21203/rs.3.rs-1118961/v1

License: (c) (1) This work is licensed under a Creative Commons Attribution 4.0 International License. Read Full License 


\title{
Impacts of fracture roughness and near-wellbore tortuous on proppant transport within hydraulic fractures
}

\author{
Di Wang ${ }^{1}$, Bingyang Bai ${ }^{2}$, Bin Wang ${ }^{2}$, Dongya $\mathrm{Wei}^{2}$, Tianbo Liang ${ }^{2, *}$ \\ ${ }^{1}$ State Key Laboratory of Shale Oil and Gas Enrichment Mechanisms and Effective \\ Development, Beijing, 100083, China; \\ ${ }^{2}$ State Key Laboratory of Oil and Gas Resources and Prospecting, China University \\ of Petroleum at Beijing, Beijing 102249, China \\ *Corresponding Author. Email Address: liangtianboo@163.com
}

\begin{abstract}
For unconventional reservoirs hydraulic fracturing design, a greater fracture length is a prime factor to optimize. However, core observation results from Hydraulic Fracturing Test Site (HFTS) show the propped fractures are far less or shorter than expected which suggests the roughness and tortuous of hydraulic fractures are crucial to sand transport. In this study a transport model of sands is first built based on experimental measurements on the height and transport velocity of sand bank in fractures with predetermined width and roughness. The fracture roughness is quantified by using surface height integral. Then, three-dimensional simulations are conducted with this modified model to further investigate the impact of fractures tortuous on sand transport, from which an analytical model is established to estimate the propped length of hydraulic fractures at a certain pumping condition. Experiments results show that height of sand bank in roughness fracture is $20-50 \%$ higher than that in smooth. The height of sand bank decreases with the reduction of slurry velocity and increases with the sand diameters increasing. Sand sizes do little effect on the transport velocity of sand bank but the increase in slurry velocity and sand volume fraction can dramatically enhance the migration velocity of sand bank. The appearance of tortuous decreases the horizontal velocity of suspended particles and results in a higher sand bank compared with that in straight fractures. When the sand bank gets equilibrium at the tortuous position, it is easy to produce vortices. So, there is a significant height of sand bank change at the tortuous position. Moreover, sand plugging can occur at the entrance of the fractures, making it difficult for the sand to transport deep in fractures. This study explains why the propped length of fractures in HFTS is short and provides an analytical model that can be easily
\end{abstract}


embedded in the fracturing simulation to fast calculate dimensions of the propped fractures network to predict length and height of propped fractures during fracturing.

Key words: Proppant transport; Fractures roughness; Tortuous fractures. 


\section{Introduction}

With the decrease of the conventional oil and gas resources, people turn their attention to the exploitation of unconventional resources. The exploitation of most of the unconventional resources benefited from the development of horizontal wells and multistage fracturing technology presently. In tight oil and gas reservoirs, the propped fracture is of great importance to provide flow channels for oil and gas production. And, the distribution of proppant significantly influences the conductivity of fractures. Thus, it is important to investigate sand bank dune form under different construction conditions. Two main factors affect the transportation and distribution of proppant in fractures. One is the property of the fractures including its width, height, roughness and tortuous, and the other is the pumping schedule including the proppant density and diameter, the rheology of fracturing fluid, the slurry velocity, and the volume fraction of proppants.

Numerous experimental and simulation studies are conducted to investigate the transport and distribution of proppant in fractures. The motion of proppant in the fractures can be divided in two aspects. The settling of proppant in the vertical direction and transport in the horizontal direction ${ }^{1}$. It can be inferred that investigating the law of proppant settling is of great significance ${ }^{2}$. Kern et al. ${ }^{3}$ found that the proppant settling velocity decreases with the particle diameter closing to fracture width. Shrivastava and Sharma ${ }^{4}$ found that the smaller particles have good suspension and can transport deeper in to the natural fractures. Harrington et al. ${ }^{5}$ put forward a modified stokes formula to describe proppant settling in non-newtonian fluid. Proppant settling velocity will decrease when the concentration of proppant increases when the particles are not clustered ${ }^{6}$. Gadde et al. ${ }^{7}$ investigated proppant settling in roughness fractures and found that the proppant settling velocity decreased when compared to the smooth facture.

As proppants flow into hydraulic fractures, they continuously precipitate from the slurry and form a sand bank, whose equilibrium height is determined by Kern et al. ${ }^{3}$ and Patankar et al. ${ }^{8}$. Wang et al. ${ }^{9}$ using the experimental data of STIM-LAB to establish a bipower law correlations for bed load transport of slurries. Gadde et al. ${ }^{7}$ put forward a modified correlation of stokes considering fluid viscosity and fracture width. And found the propped length of fractures increase when incorporated it into UTFRAC-3D to predict proppant distribution in fractures. Proppant distribution is uneven within the torturous fractures in shale reservoirs ${ }^{10}$. Roughness of fractures face can increase the interaction between particles and rock, which increases the uncertainty of flow ${ }^{11}$. Huang et al. ${ }^{12}$ also investigated the proppant distribution in roughness fractures and found that form of sand bank is not always the same as that in smooth fractures. However, the roughness of fractures surfaces is not quantitatively used in these studies. Presently, the quantification 
of fracture roughness are mainly as follows. ${ }^{13}$ proposed Joint Roughness Coefficient (JRC) to characterize the roughness of different type of rock surface. Fractal dimension is another method to quantify the roughness of fracture which can be obtained by the variogram analysis, power spectral density and triangular prism. Besides, a relatively simple method to quantify the fracture roughness is surface integral ration, which is the ration between total fractures surface area and the projection area of rough surface ${ }^{14}$.

The simulation of proppant transport can be mainly divided into two categories. One is the Eulerian-Eulerian method and the other is Eulerian-Lagrangian method. The most common method used to simulate the proppant transportation in filed scale is EulerianEulerian method. Eulerian-Eulerian method refers to use of mass conservation equation to calculate fluid and proppant in Eulerian grid. The transport of proppant is assumed as the change of proppant volumetric concentration. It may not accurate enough to arrest every particle movement but saves a lot of calculation time. Eulerian-Lagrangian method is another method to simulate proppant transport and distribution method. Discrete Particle Method (DPM) and Computational Fluid Dynamics-Discrete Element Method (CFD-DEM) are two mainly used Eulerian-Lagrangian method. The DPM model is suitable to solve the proppant transport with low concentration. CFD-DEM can model every particle movement and high concentration of proppant transport. Due to track the movement of each particle. CFD-DEM is more time costing and have a large amount of calculation. This method can describe the particle transport accurately but difficult for field scale simulation. A dimension reduction strategy coupled with Eulerian-Eulerian method is used to investigated the proppant transportation in filed scale by $\mathrm{Hu}$ et al. ${ }^{1}$. Suri et al. ${ }^{15}$ investigated the proppant transport in roughness facture and found the roughness of fractures can provide an additional force for proppant transport in fractures for a long distance.

Of the previous experiments and simulation results, it is known that the injected proppant can form a regular sand dune in the fractures and transport deep into the fractures as slurry continuously injected. Is the distribution of proppant in real fractures really like this?

Hydraulic Fracture Test Site project aimed to recover cores from a stimulated volume, making a further observation of the proppant distribution in the real fractures. However, core results show an unexpected distribution of proppant. Many of the cores collected held little of sand ${ }^{16}$. Moreover, the distribution of proppant in the fractures is nonuniform. Many of the proppants are found in the fractures near wellbore and little proppant is discovered in the secondary fractures ${ }^{17}$.

Although many numerical and experimental work was conducted to investigate the proppant transportation and distribution in fractures including the proppant-bed 
equilibrium height, however, the proppant-bed length is seldom studied. As for the proppant distribution in fractures, sand bank height is a significant parameter to depict the vertical sand coverage. However, the propped length of fractures in roughness field scale fractures is unclear. In this study, an analytical model is proposed to investigate the proppant transport and distribution in roughness fractures which gives a prediction in field scale. In addition, a tortuous fracture model is applied to explain the unevenness of proppant distribution. 


\section{Model build up}

In this study, the principal purpose is to explain transportation and distribution of proppant in roughness and tortuous fractures. The Eulerian-Lagrangian method coupled with Dense Discrete Particle Model (DDPM) is applied to solve this problem of granular flow with a high volume-fraction of particles.

\subsection{Experiment and simulation methods}

Firstly, a large transparent fracture-flow model with smooth fracture surfaces is used to observe the formation and transport of sand bank, and compared with ones in the published studies. This model is composed of two parallel Plexiglas plates, a centrifugal pump (with the maximum flow rate of $8 \mathrm{~m}^{3} / \mathrm{h}$ ), an agitator tank (with a maximum volume of 200L) and a flowmeter (with a maximum flow rate of $8 \mathrm{~m}^{3} / \mathrm{h}$ ), as shown in Fig.1.The transparent fracture-flow model is used to visualize the sand transport in a narrow and flat fracture, whose results can be used to validate the numerical model in this study. In the transparent fracture-flow experiments, silica sand and tap water with a certain sand volume fraction is continuously injected into a fracture with dimensions of $1.5 \mathrm{~m}$ (length) $\times 0.3 \mathrm{~m}$ (height) $\times 0.004 \mathrm{~m}$ (width); other parameters can be referred in Table 1 shown below. Shapes of sand bank and equilibrium sand heights are shown in the left column of Fig 8 when different slurry velocities are used.

Experiments are conducted using 20/40 mesh sand, with $7.4 \%$ sand and a slurry velocity of $0.2 \mathrm{~m} / \mathrm{s}, 0.4 \mathrm{~m} / \mathrm{s}$ and $0.6 \mathrm{~m} / \mathrm{s}$. As is shown in Fig.2, sands precipitate from the slurry and gradually form a sand bank; the height of the sand bank within the fractures increases with time until reaches an equilibrium height, which is similar to ones reported in the previous studies ${ }^{9,12,18}$. 


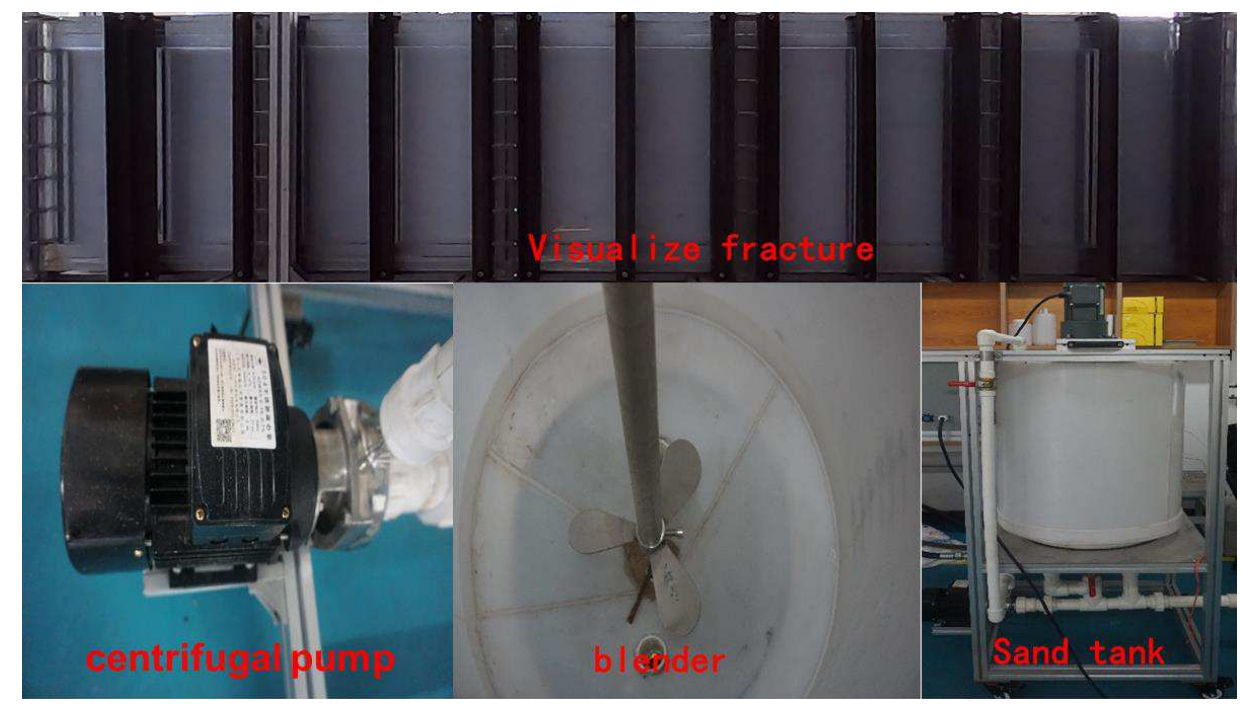

Fig.1 The transparent fracture-flow model

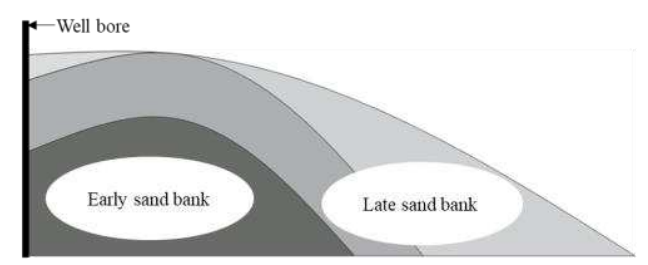

Traditionally sand bank form (modified from Wang et al., 2003)

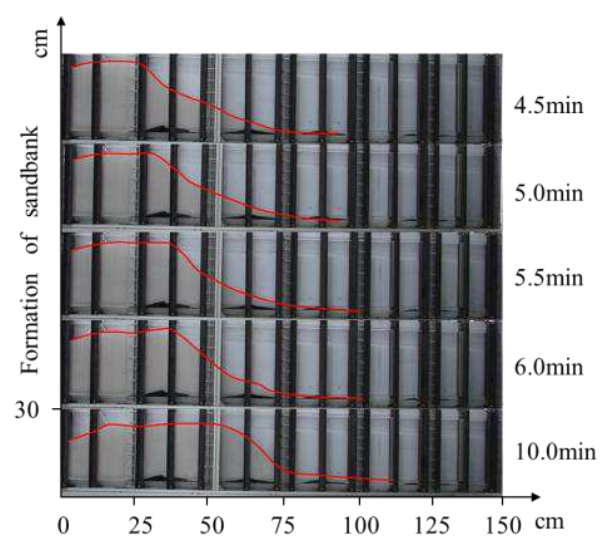

Fig.2 Comparison of sand bank, slurry velocity $0.02-0.2 \mathrm{~m} / \mathrm{s}^{9}$

In the simulation, the same parameters are used in experiments and numerical model. The simulation results match well with the experimental results when fractures surfaces are flat.

Table.1 Parameters of experiments and simulations

\begin{tabular}{ll}
\hline parameters & Values \\
\hline slurry velocity, $\mathrm{m} / \mathrm{min}$ & $12,24,36$ \\
sand diameter, $\mathrm{mm}$ & 0.325 \\
fracture width, $\mathrm{mm}$ & 4 \\
fluid viscosity, $\mathrm{Pa} \cdot \mathrm{s}$ & 0.001 \\
sand density, $\mathrm{kg} / \mathrm{m}^{3}$ & 2600 \\
volume fraction of sand & $7.3 \%$ \\
\hline
\end{tabular}


Then, the simulation model is conducted to understand the effect of fractures roughness on sand transport and distribution. The transport velocity and equilibrium height of the formed sand bank within the fractures are compared among cases with different slurry velocity, sand sizes, sand volume fraction, and fractures surface roughness shown in Table 2.

Table.2 Parameters in simulation cases

\begin{tabular}{ll}
\hline parameters & Values \\
\hline slurry velocity, $\mathrm{m} / \mathrm{min}$ & $12,24,36,66,96,126$ \\
sand diameter, $\mathrm{mm}$ & $0.208,0.325,0.425,0.739$ \\
fracture width, $\mathrm{mm}$ & 4 \\
sand volume fraction & $4.7 \%, 7.3 \%, 10 \%$ \\
Ra (fracture roughness), & $0.39,0.59,0.79$ \\
\hline
\end{tabular}

\subsection{Rough and tortuous model development}

An outcrop sample is cut into cubes with side lengths of $300 \mathrm{~mm}$ which is shown in Fig.3. Then, rough fractures surfaces are obtained through the tri-axial hydraulic fracturing with the mimicked reservoir condition. The rough fractures surfaces are 3D scanned to calculate their Ra. Then this pair of fractures surfaces is duplicated through 3D printing and installed into the transparent fractures flow model, 20/40 mesh sands with a volume fraction of $7.4 \%$ are injected into the model for observing the formation and transport of the sand bank. A 3D fracture model is built and the dimension of the fracture is consistent with our experimental fracture-flow model. The total generated mesh number of the fracture is 151392 shown in Fig.4 and all of the mesh meet the calculation requirements. Experimental results are further compared with simulation results using with our simulation model.

Roughness of a fractures surface can be quantified in different ways. Babadagli et al. $(2015,2015)$ used variogram $\left(D_{v a}\right)$, power spectral density $\left(D_{p s d}\right)$, and triangular prism analyses $\left(D_{t p}\right)$ to describe the roughness of a fractures. In this study, the integral of surface heights is used, as defined in Eq. (1). In this study, conglomerate and shale fractures is used which have Ra values of 0.39 and 0.74 respectively, as shown in Fig. 6.

$$
\boldsymbol{R}_{a}=\frac{1}{l} \int_{0}^{l}|y(x)| d x
$$

1 is the sampling length, and $\mathrm{y}(\mathrm{x})$ is the heights of points on the chosen line.

In ANSYS Fluent, the roughness of a fracture surface is defined by Ks. As is shown in Fig.5, it is assumed that the rough fracture surface is formed by a layer of closely- 
packed balls with identical radius, and the radius of the ball is Ks. When Ks equals to zero, a smooth fracture surface is obtained.
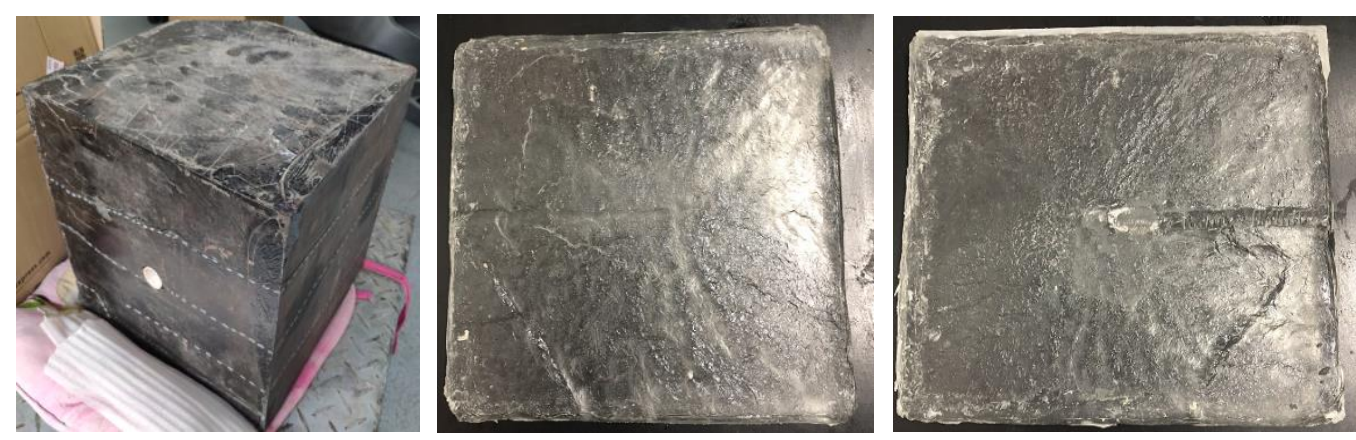

Fig.3 Outcrop sample and duplicated fractures
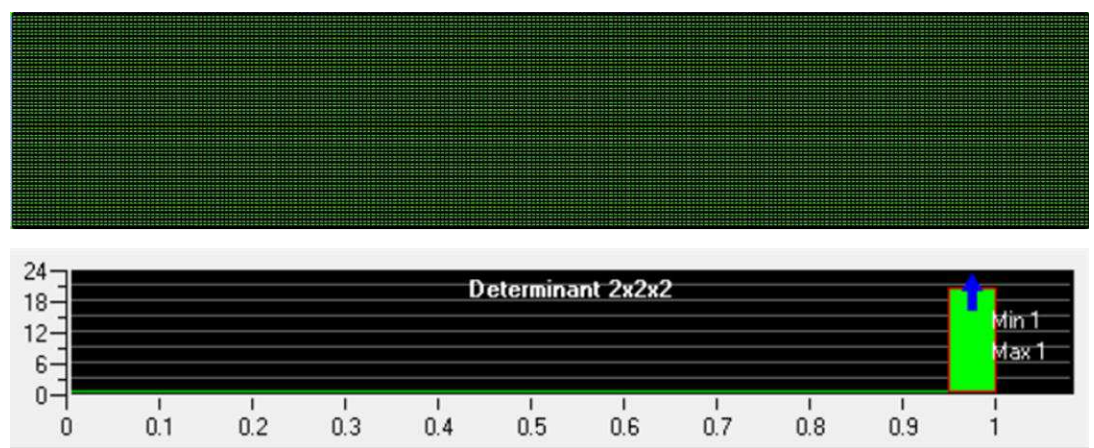

Fig.4 Generated mesh and mesh quality

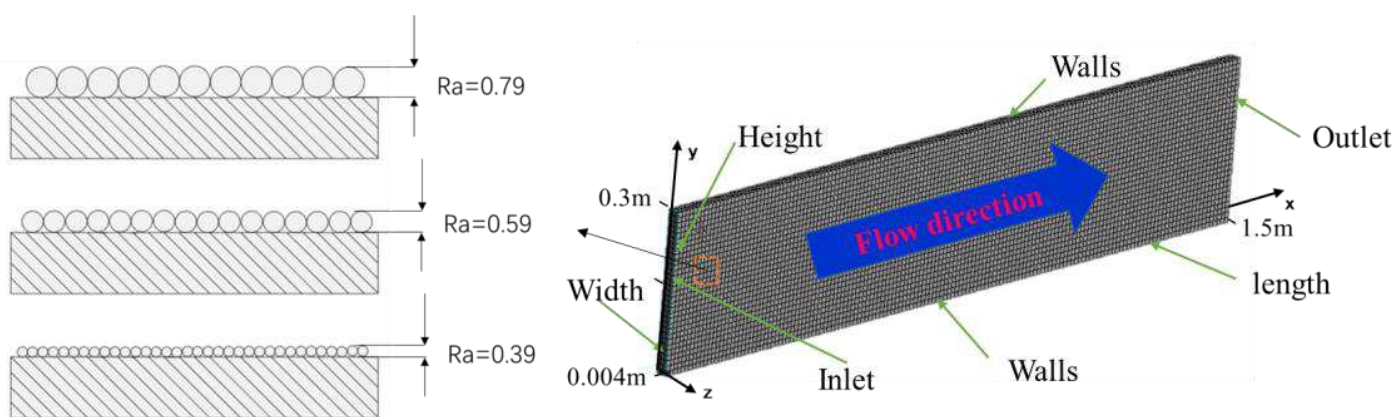

Fig.5 Straight roughness fracture model 

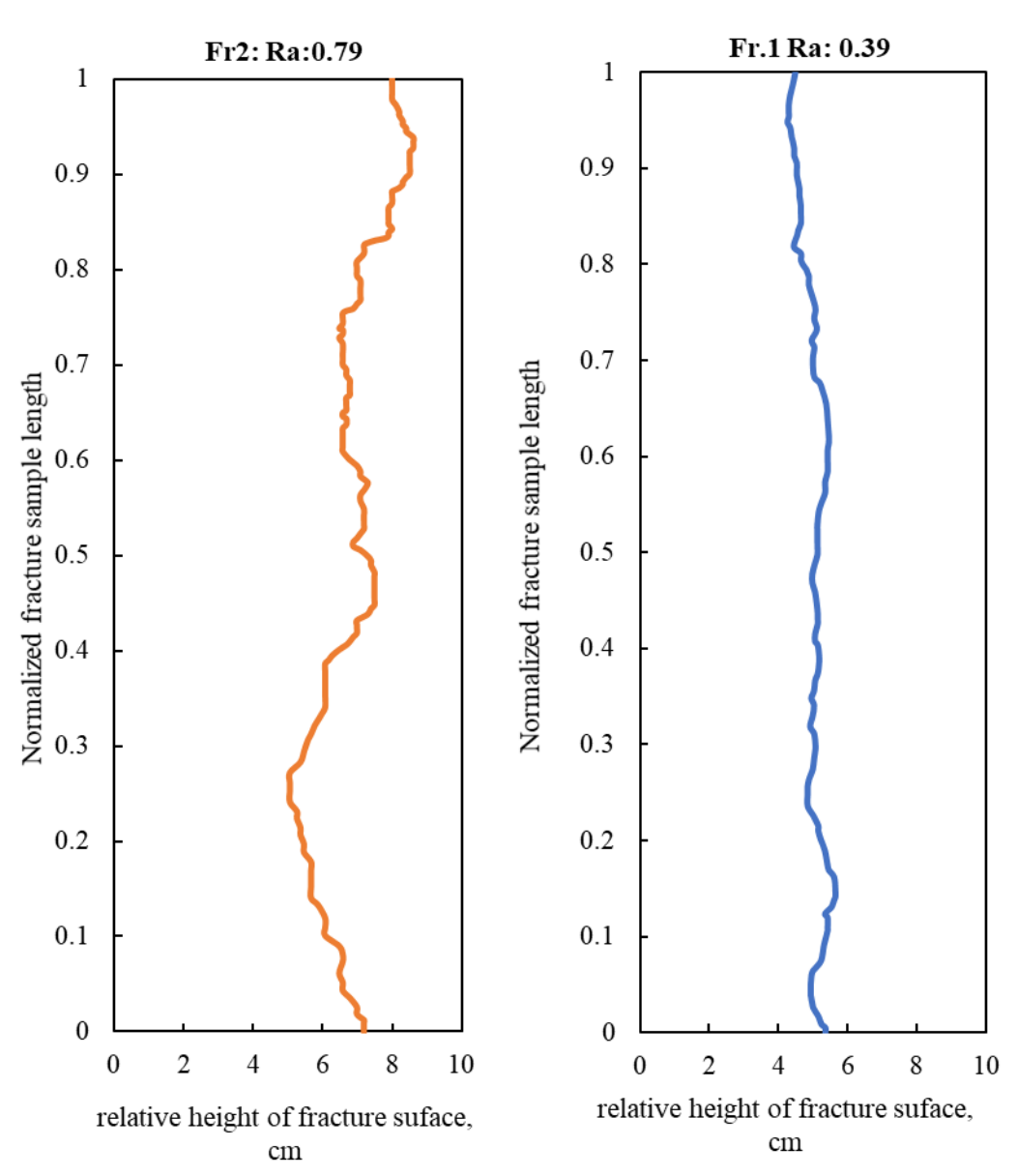

Fig.6 Roughness fracture with different Ra

Besides the straight fracture, a fracture with a curvature is used to study the sand transport in fractures with near wellbore tortuosity as is shown in Fig.7. In this tortuous fractures model, the angle of the curvature is $120^{\circ}$ and two kinds of curved fractures are used which are $0.2 \mathrm{~m}$ and $0.75 \mathrm{~m}$ from the velocity-inlet boundary respectively. Three sensitive parameters are studied including slurry velocity, volume fraction of sands and sands diameter. The parameters in the simulation process are shown in Table 3.

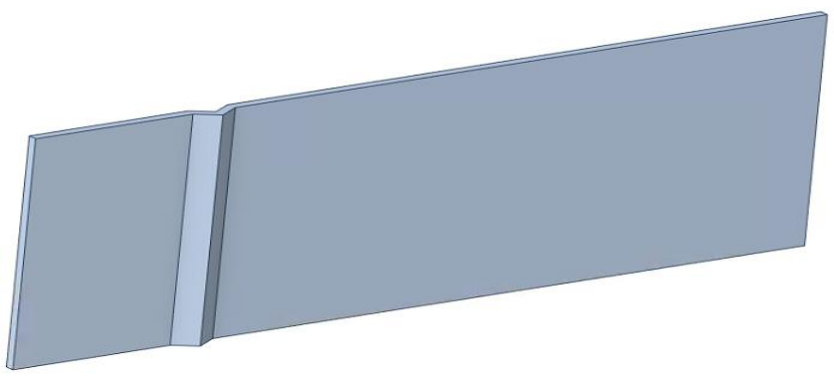

Fig.7 Tortuous fracture model 
Table.3 Parameters of simulation model

\begin{tabular}{lcll}
\hline & straight facture & tortuous facture 1 & tortuous facture 2 \\
\hline length, $\mathrm{m}$ & 1.5 & 1.5 & 1.5 \\
width, $\mathrm{m}$ & 0.004 & 0.004 & 0.004 \\
height, $\mathrm{m}$ & 0.3 & 0.3 & 0.3 \\
tortuous angle, degree & & 120 & 120 \\
tortuous length, m & & 0.06 & 0.06 \\
tortuous position, $\mathrm{m}$ & & 0.75 & 0.2 \\
tortuous width, $\mathrm{m}$ & & 0.00346 & 0.00346 \\
\hline
\end{tabular}

\subsection{Numerical model}

The Eulerian-Eulerian method and Eulerian-Lagrangian method are two main methods applied to investigate sand transport and distribution in fractures. Sand and fluid are considered as two phases respectively in Eulerian-Eulerian method, and both the fluid and sand solved in Eulerian grids. Eulerian-Lagrangian method can be roughly divided in two methods including Discrete Particle method (DPM) and Computational Fluid Dynamics-Discrete Element Method (CFD-DEM). In DPM method, the sands with similar properties are packed into parcels which can dramatically decrease the calculational cost. In CFD-DEM method the movement of each individual sand is calculated in lagrangian method, which significantly increases the computational cost. In this study, Eulerian-Lagrangian method with the Dense Discrete Phase Model (DDPM) model is chosen to study the sand transport and sand bank within a fracture. Some of assumptions in this model are as follows.

Fluid is assumed as a continuous phase; and is solved in Eulerian grid. Sand is assumed as a discrete phase and is tracked by a Lagrangian approach and mapped back to the Eulerian grid. The force between sands is solved by Kinetic Theory of Granular Flows model. During the sand injection, fracture propagation is not considered.

To solve the equations, the inlet boundary is chosen as the velocity inlet where the slurry is injected, and the outlet boundary is set as one atmospheric pressure. Roughness of fractures surfaces are controlled by adjusting Ks which is embedded in the boundary condition. DDPM is a well-established model and a brief introduction is as follows.

The continuity equation can be expressed as ${ }^{19}$

$$
\frac{\partial}{\partial t}\left(\alpha_{f} \rho_{f}\right)+\nabla\left(\alpha_{f} \rho_{f} \overrightarrow{v_{f}}\right)=0
$$




$$
\frac{\partial}{\partial t}\left(\alpha_{s} \rho_{s}\right)+\nabla\left(\alpha_{s} \rho_{s} \overrightarrow{v_{s}}\right)=0
$$

The $\alpha_{f}$ and $\alpha_{s}$ are volume fraction of fluid and solid respectively. The $\rho_{f}$ and $\rho_{s}$ are density of the fluid and solid respectively. The $v_{f}$ and $v_{s}$ are velocity of fluid and solid respectively.

The motion equation can be expressed as ${ }^{19}$

$$
\begin{aligned}
& \frac{\partial}{\partial t}\left(\alpha_{f} \rho_{f} \overrightarrow{v_{f}}\right)+\nabla\left(\alpha_{f} \rho_{f} \overrightarrow{v_{f}} \overrightarrow{v_{f}}\right) \\
& =-\alpha_{f} \nabla p+\nabla \overline{\overline{\tau_{f}}}+\alpha_{f} \rho_{f} \vec{g}+\beta\left(\overrightarrow{v_{s}}-\overrightarrow{v_{f}}\right) \\
& \frac{\partial}{\partial t}\left(\alpha_{s} \rho_{s} \overrightarrow{v_{s}}\right)+\nabla\left(\alpha_{s} \rho_{s} \overrightarrow{v_{s}} \overrightarrow{v_{s}}\right) \\
& =-\alpha_{s} \nabla p+\nabla \overrightarrow{\overline{\tau_{s}}}+\alpha_{s} \rho_{s} \vec{g}+\beta\left(\overrightarrow{v_{f}}-\overrightarrow{v_{s}}\right) \\
& \overline{\overline{\tau_{f}}}=\alpha_{f} \mu_{f}\left(\nabla \overrightarrow{v_{f}}-\nabla \overrightarrow{v_{f}}\right)-\frac{2}{3} \alpha_{f} \mu_{f}\left(\nabla \overrightarrow{v_{f}}\right) \overline{\bar{I}} \\
& =\mu_{\overline{\tau_{s}}}=\mu_{s}\left(\nabla \overrightarrow{v_{s}}-\nabla{\overrightarrow{v_{s}}}^{T}\right)+\left(\lambda_{s}-\frac{2}{3} \mu_{s}\right)\left(\nabla \overrightarrow{v_{s}}\right) \overline{\bar{I}}
\end{aligned}
$$

$\mathrm{P}$ is the pressure of the all phases. $\overline{\overline{\tau_{f}}}$ and $\overline{\overline{\tau_{s}}}$ are the stress tensors of the fluid and solid respectively. $\vec{g}$ is the acceleration of gravity. $\beta$ is the Gidaspow drag force coefficient and is suitable for various volume fraction of solid phase which can be written as follows ${ }^{19}$.

$$
\begin{gathered}
\beta=150 \frac{\alpha_{s}\left(1-\alpha_{f}\right) \mu_{f}}{\alpha_{f} d_{s}^{2}}+1.75 \frac{\alpha_{s} \rho_{f}\left|\overrightarrow{v_{s}}-\overrightarrow{v_{f}}\right|}{d_{s}}, \alpha_{s} \geq 0.2 \\
\beta=0.75 C_{D} \frac{\alpha_{s} \alpha_{f} \rho_{f}\left|\overrightarrow{v_{s}}-\overrightarrow{v_{f}}\right|}{d_{s}} \alpha_{f}^{-2.65}, \alpha_{s} \leq 0.2
\end{gathered}
$$

The $d_{s}$ is the diameter of the particle. $C_{d}$ is the drag coefficient.

The motion equation of particle phase in DDPM model is not solved in Eq. (5). It is computed by ${ }^{19,20}$

$$
\begin{gathered}
\frac{d \overrightarrow{v_{s}}}{d t}=\frac{\vec{g}\left(\rho_{s}-\rho_{f}\right)}{\rho_{s}}+F_{D}\left(\overrightarrow{v_{f}}-\overrightarrow{v_{s}}\right)+\overrightarrow{F_{K T G F}} \\
F_{D}=\frac{18 \mu_{f}}{\rho_{s} d_{s}^{2}} \frac{C_{D} \operatorname{Re}_{s}}{24}
\end{gathered}
$$




$$
\overrightarrow{F_{K T F G}}=-\frac{1}{\alpha_{s} \rho_{s}} \nabla \square \overline{\tau_{s}}
$$

The $\mathrm{Re}_{\mathrm{s}}$ and $\mathrm{C}_{\mathrm{d}}$ are expressed by ${ }^{19}$

$$
\begin{gathered}
\operatorname{Re}_{s}=\frac{d_{s} \rho_{f}\left|\overrightarrow{v_{s}}-\overrightarrow{v_{f}}\right|}{\mu_{f}} \\
C_{D}=\frac{24}{\alpha_{f} \operatorname{Re}_{s}}\left[1+0.15\left(\alpha_{f} \operatorname{Re}_{s}\right)^{0.687}\right]
\end{gathered}
$$

Where $\mathrm{Re}_{\mathrm{s}}$ is Reynolds number of soild.

In kinetic theory of granular flow (KTGF), the shear viscosity of solid $\left(\mu_{\mathrm{s}}\right)$ contains kinetic viscosity $\left(\mu_{\mathrm{s}, \mathrm{kin}}\right)$, collisional viscosity $\left(\mu_{\mathrm{s}, \mathrm{col}}\right)$ and fractional viscosity $\left(\mu_{\mathrm{s}, \mathrm{fri}}\right)$.

$$
\mu_{s}=\mu_{s, k i n}+\mu_{s, c o l}+\mu_{s, f r i}
$$

Kinetic viscosity can be expressed as ${ }^{21}$

$$
\mu_{s, k i n}=\frac{10 d_{s} \rho_{s} \sqrt{\Theta_{s} \pi}}{96 \alpha_{s} g_{0}(1+e)}\left[1+\frac{4}{5} \alpha_{s} g_{0}(1+e)\right]^{2}
$$

$\Theta_{S}$ is the granular temperature. The $\mathrm{g}_{0}$ is the radial distribution function which represents the resistance of particles to deformation and can be obtained by ${ }^{22}$

$$
g_{0}=\left(1-\left(\frac{\alpha_{s}}{\alpha_{s, \max }}\right)^{\frac{1}{3}}\right)^{-1}
$$

The collisional viscosity can be written by ${ }^{20}$

$$
\mu_{s, c o l}=\frac{4}{5} \alpha_{s} d_{s} \rho_{s} g_{0}(1+e)\left(\frac{\Theta_{s}}{\pi}\right)^{\frac{1}{2}}
$$

The fractional viscosity can be written by ${ }^{23}$

$$
\begin{gathered}
\mu_{s, \text { fri }}=\frac{P_{\text {friction }} \operatorname{Sin} \Phi}{2 \sqrt{I_{2 D}}} \\
P_{\text {friction }}=0.1 \alpha_{s} \frac{\left(\alpha_{s}-\alpha_{s, \min }\right)^{2}}{\left(\alpha_{s, \max }-\alpha_{s}\right)^{3}} \\
\lambda_{s}=\frac{4}{3} \alpha_{s} d_{s} \rho_{s} g_{0}(1+e)\left(\frac{\Theta_{s}}{\pi}\right)^{\frac{1}{2}}
\end{gathered}
$$

Where the $\phi$ is angle of flow direction.

The pressure of solid phase can be expressed by ${ }^{24}$

$$
P_{s}=\alpha_{s} \rho_{s} \Theta_{s}+2 \alpha_{s}^{2} \rho_{s} \Theta_{s} g_{0}(1+e)
$$




\section{Results and discussion}

\subsection{Validation of numerical model}

Fig 8 shows the results of the comparison between simulation results and experiment results. Water and 40/70 mesh sands are injected at the inlet at different velocity which are $0.2 \mathrm{~m} / \mathrm{s}, 0.4 \mathrm{~m} / \mathrm{s}$, and $0.6 \mathrm{~m} / \mathrm{s}$.

When the injection rate is $12 \mathrm{~m} / \mathrm{min}$, the equilibrium height of the sand bank is 5.75 $\mathrm{cm}$ and $5.42 \mathrm{~cm}$ for experiment and simulation results. The comparison between experiments and simulation results with an average percentage error of $3.34 \%$ for the equilibrium height of sand bank. This suggests a well consistency between experiments and simulation results.

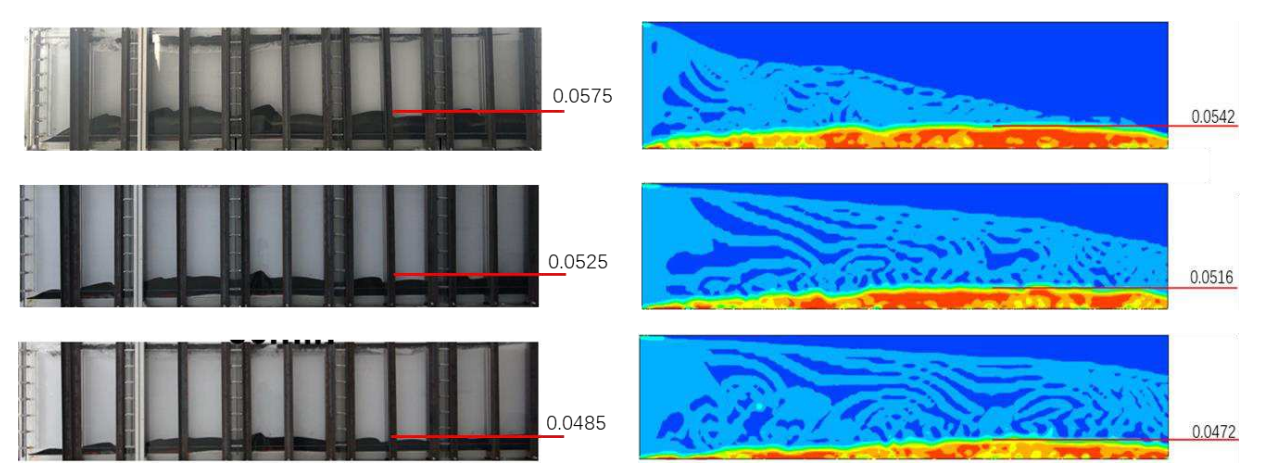

Fig.8 The results comparison between experiments and simulation (the red lines show the equilibrium height of the sand bank which the unit is meter)

\subsection{Sand transport in roughness fractures}

\subsubsection{Effect of slurry velocity}

The sensitivity analysis in this section includes three key factors containing slurry velocity, sand diameter, sand volume fraction. At first, the slurry velocity is changed, keeping all other factors constant.

Fig 9 shows the change of sand distribution in different cases when the slurry injection velocity is $12 \mathrm{~m} / \mathrm{min}, 24 \mathrm{~m} / \mathrm{min}$, and $36 \mathrm{~m} / \mathrm{min}$. When the injection velocity is $12 \mathrm{~m} / \mathrm{min}$, the equilibrium height of the sand bank is $13.00 \mathrm{~cm}$. In the region where the sand bank is stabilized, the sand volume fraction is around $0.59-0.63$, which is the density of the sphere random packing. In the region where sands are floating in the fracturing fluid, the volume fraction is $7.3 \%$, which is identical to that of the slurry injected. When the sand bank is formed and equilibrium height is reached, the farthest 
horizontal distance reached after the complete settlement of sands can be found, as pointed by a black arrow in Fig 12. This horizontal distance is $3.63 \mathrm{~m}$ when the slurry injection rate is $96 \mathrm{~m} / \mathrm{min}$, and it decreases to $0.46 \mathrm{~m}$ when the slurry injection velocity is $12 \mathrm{~m} / \mathrm{min}$ (Fig 13).

From the simulation, locations of the sand bank front can be marked at different time slices, from which transport rate of the sand bank can be calculation. Fig.9 shows a schematic diagram to calculate the propagation rate of the propped fractures. As is shown in Fig 11, it increases with injection rate and the volume fraction of sand injected.

The simulation results of sand volume fraction contour plots are shown in Fig.10. Three cases of variation in slurry injection velocity are $12 \mathrm{~m} / \mathrm{min}, 24 \mathrm{~m} / \mathrm{min}, 36 \mathrm{~m} / \mathrm{min}$ respectively. On comparison of sand volume fraction contour plot for different slurry injection velocity. It can be found that as the velocity of slurry increases the sand bank height decreases and the fractures propped length increases. Fig. 11 shows the fractures propped length and propped height of the simulation results of different slurry velocity. As the slurry velocity increases the propped height decrease and the propped length increase. A new parameter entry effect length shown in Fig. 12 is put forward to explain this phenomenon which represents the sand settling position at the farthest of sand bank. As is shown in Fig.13, the entry effect length and horizontal slurry velocity have a linear relationship which suggests that increasing the horizontal slurry velocity dose no effect on the sand settling velocity. Since the particles settling velocity are not disturbed by the horizontal slurry velocity, at a certain same time, more sand will be transported away from inlet boundary. Moreover, the high slurry injection velocity stronger the force between fluid phase and solid phase resulting more sand carried to the deeper of fractures and lead to a shorter sand bank.

The present study of the sand distribution to injection velocity suggests that it is of great importance in optimizing sand transport and distribution. As for slick water fracturing, a higher injection velocity will be a good approach to improve the fracturing results.
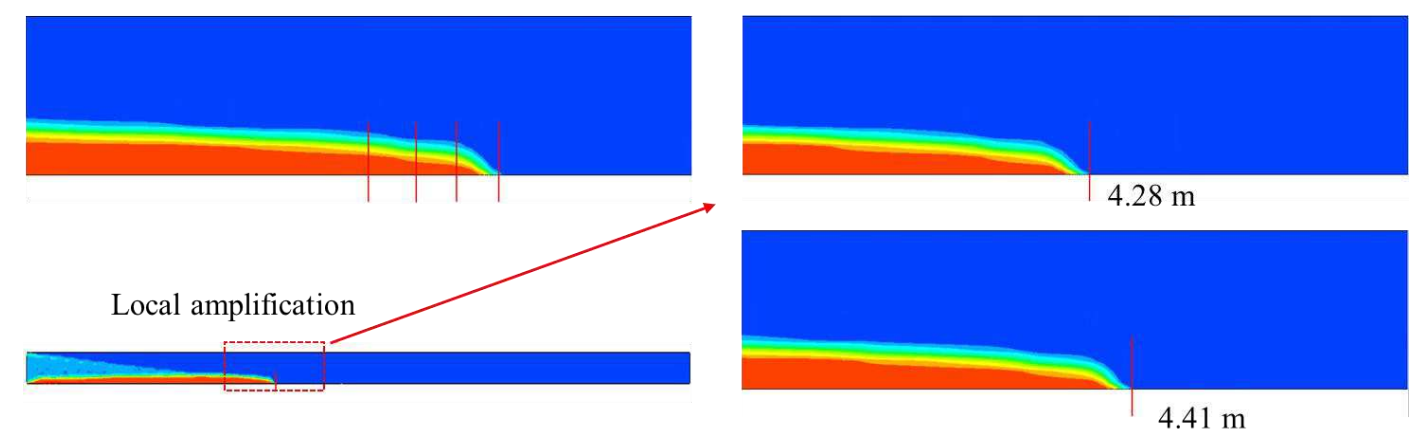
Fig.9 Acquisition of propagation rate of the propped fractures

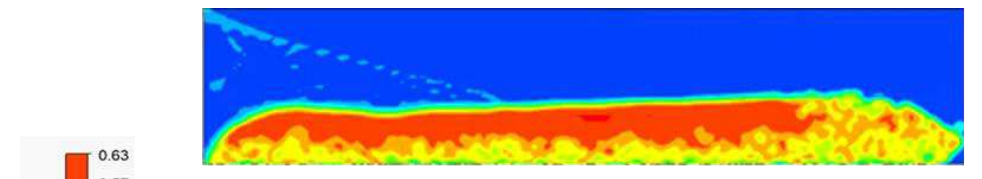

(a) $0.2 \mathrm{~m} / \mathrm{s}, 0.739 \mathrm{~mm}, 7.3 \%$ sand

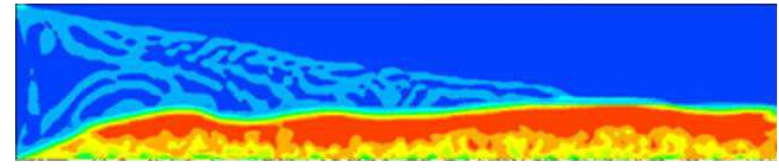

(b) $0.4 \mathrm{~m} / \mathrm{s}, 0.739 \mathrm{~mm}, 7.3 \%$ sand

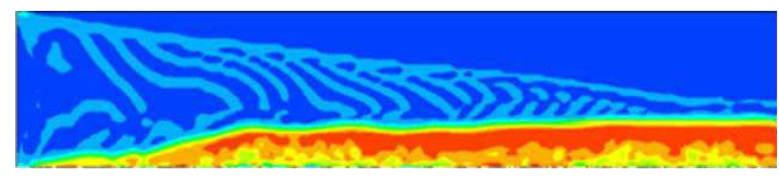

(c) $0.6 \mathrm{~m} / \mathrm{s}, 0.739 \mathrm{~mm}, 7.3 \%$ sand

Fig.10 Comparison of sand distribution for different slurry velocities

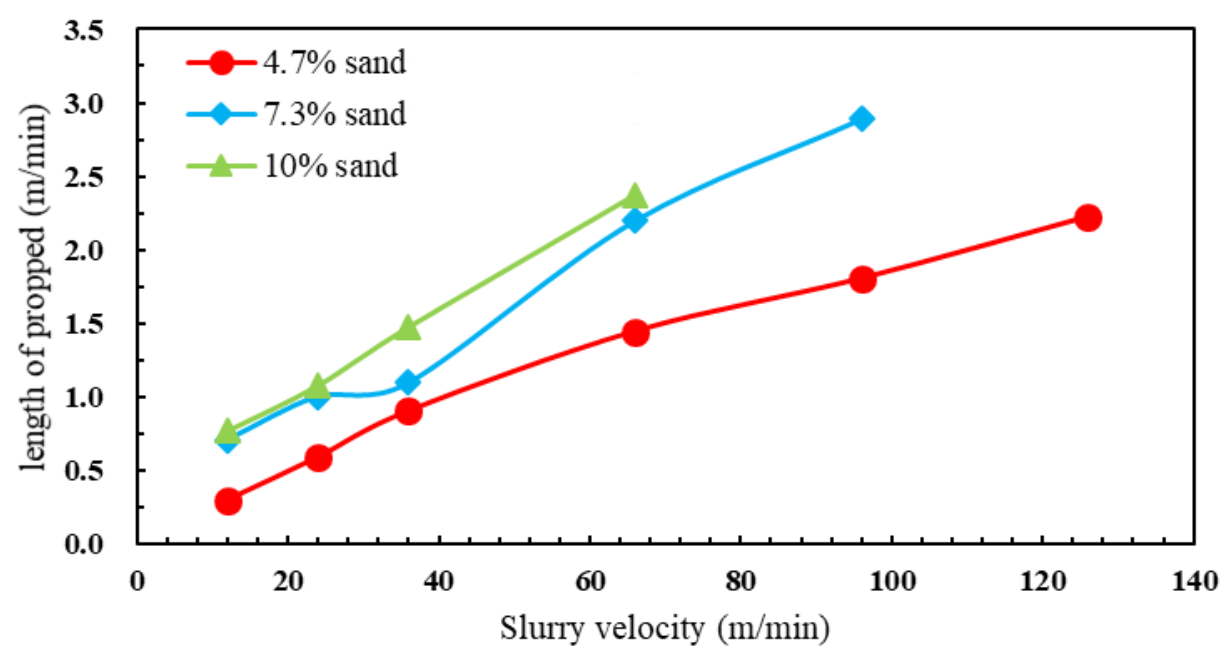

Fig.11 Changes of propagation rate of the propped fractures with slurry injection rate and sand volume fraction

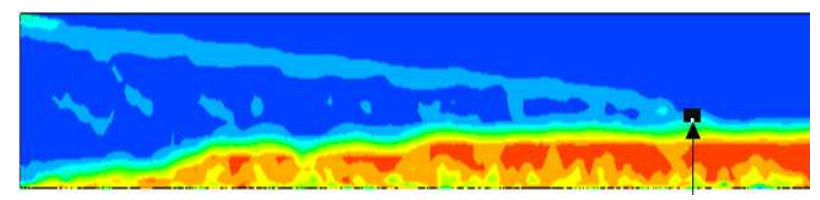

Fig.12 Sand distribution at the end of simulation (Black arrow points to the farthest location of sand settlement) 


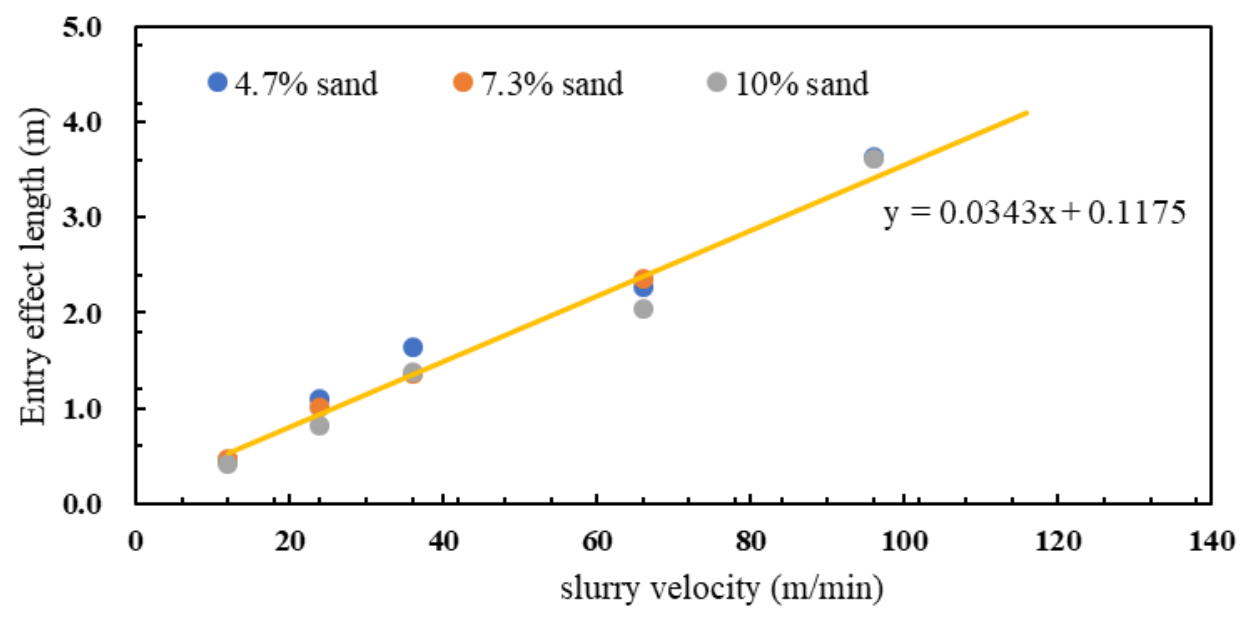

Fig.13 Entry effect length with slurry horizontal velocity

\subsubsection{Effect of sand volume fraction}

After the investigation of the effect of slurry velocity effect. The effect of sand volume fraction is studied. Fig 14 shows the change of sand distribution in different cases when the sand injection is $4.7 \%, 7.3 \%$, and $10.0 \%$. When the sand injection is $7.3 \%$, the length of sand bank is $0.85 \mathrm{~m}$ and increases to $0.98 \mathrm{~m}$ when the sand injection is $10.0 \%$. The sand bank length increases with the volume fraction of sand injection as is shown in Fig 11.

Improving the volume fraction of sand injection can effectively reduce the time for sand bank to reach the equilibrium height and accelerate the rate of sand bank moving forward. In other words, in the same fracturing time if the volume fraction of injected sand is increased, the longer of the fractures would be propped. Therefore, in order to reduce field working time, increasing the volume fraction of sand injection is a practical approach. During the actual production process, the hydraulic fractures are not always straight but tortuous and nonuniform fractures. Thus, by using high volume fraction of sand can cause sand plug, especially using low viscosity fracturing fluid like slick water. A reasonable volume fraction of sand injected will be a good choice that can decrease the hydraulic fracturing time and avoid the sand plug. 


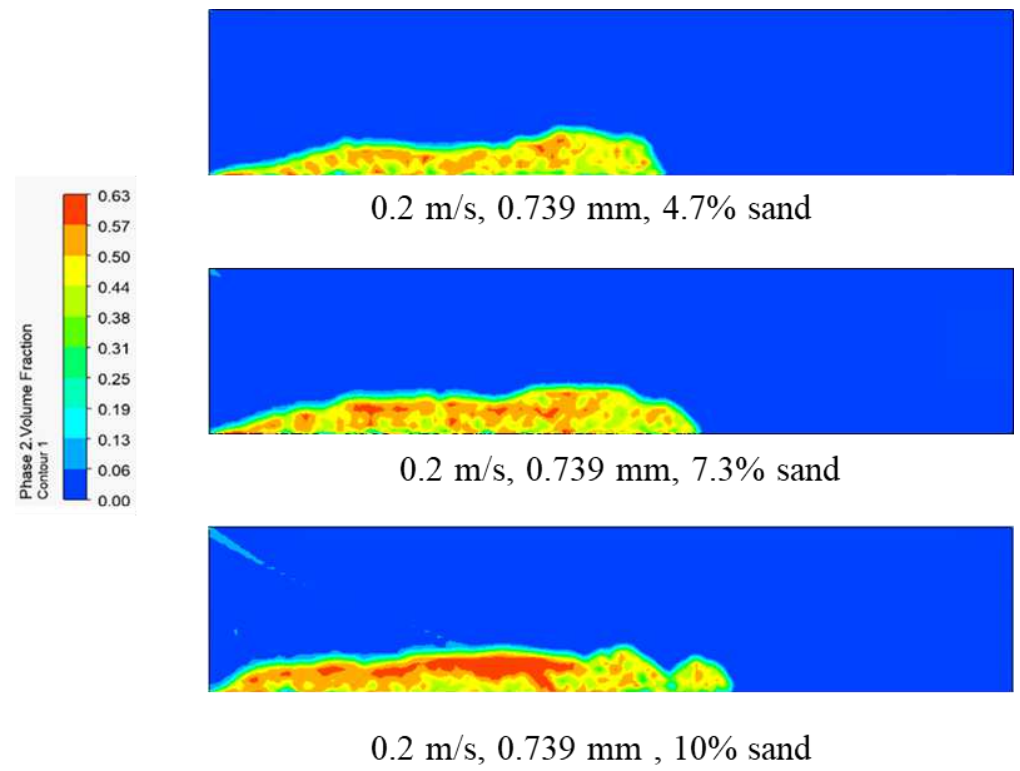

Fig.14 Comparison of sand distribution for different sand volume fraction

\subsubsection{Effect of sand diameter}

Next, the effect of sand diameter on sand bank equilibrium height and the propped length is studied. Fig 15 shows the change of sand distribution in different cases when the sand diameters are $0.208 \mathrm{~mm}, 0.325 \mathrm{~mm}, 0.425 \mathrm{~mm}$ and $0.739 \mathrm{~mm}$. When the sand diameter is $0.739 \mathrm{~mm}$, the equilibrium height of the sand bank is $13.00 \mathrm{~cm}$ and it decreases to 2.85 $\mathrm{cm}$ when the sand diameter is $0.285 \mathrm{~mm}$. Fig. 16 shows the relationship between sand bank height and sand diameter and slurry velocity. It can be found that as the diameter decreases, the sand bank equilibrium height apparently decreases which can be seen in the left of Fig.18 and Fig.19. The rate of propped length is not affected by the sand diameter which can be seen in the right column of Fig. 18 .

To understand the reason of this phenomenon, a graph is plotted against variables entry effect length/slurry velocity and sand diameter as is shown in Fig.17, where entry effect length is clarified earlier. It can be interpreted from that as the sand diameter increases, the ration of entry effect length/slurry velocity decrease, which suggests that large diameter of sand tend to settling at the fracture entrance. Thus, it can be reasonably to explain the formation process of sand bank. In the case of the same horizontal injection flow rate, in the same time, due to the large sedimentation velocity of the sand of large particle size, most of the sand settled, while the small sizes of particles can be transported to away from the wellbore. Thus, at the beginning of sand formation, large size of particle shows high sand bank. Moreover, sands with large particle sizes have large mass and large inertia. When the inlet flow rate is constant, the distance between the sand bank and 
the top of fracture is smaller, the velocity will be larger. So, small size of particle can be transported easily by low velocity of fracturing fluid while large size of particle requires high velocity of fracturing fluid to wash away. Therefore, the sand bank height of different particle diameter shows different.

The sedimentation speed of large particle is fast, but the sand bank is high. The sedimentation speed of small particles is slow, but the sand bank is short, so the propped rate of sands of large and small particles in fractures is relatively close.

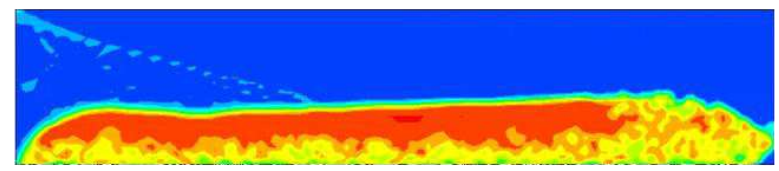

$0.2 \mathrm{~m} / \mathrm{s}, 0.739,0.130 \mathrm{~m}, 7.3 \%$ sand

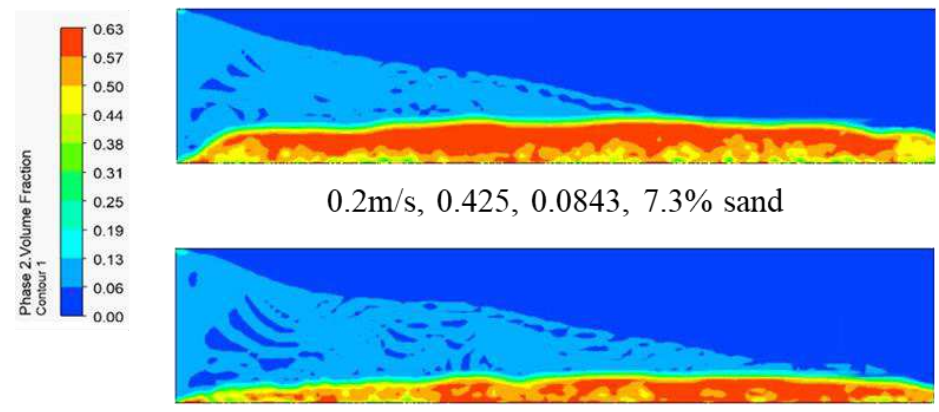

$0.2 \mathrm{~m} / \mathrm{s}, 0.322,0.0542,7.3 \%$ sand

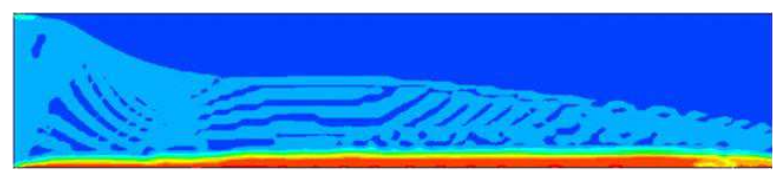

$0.2 \mathrm{~m} / \mathrm{s}, 0.208,0.0285,7.3 \%$ sand

Fig.15 Comparison of sand distribution for different sand diameter 


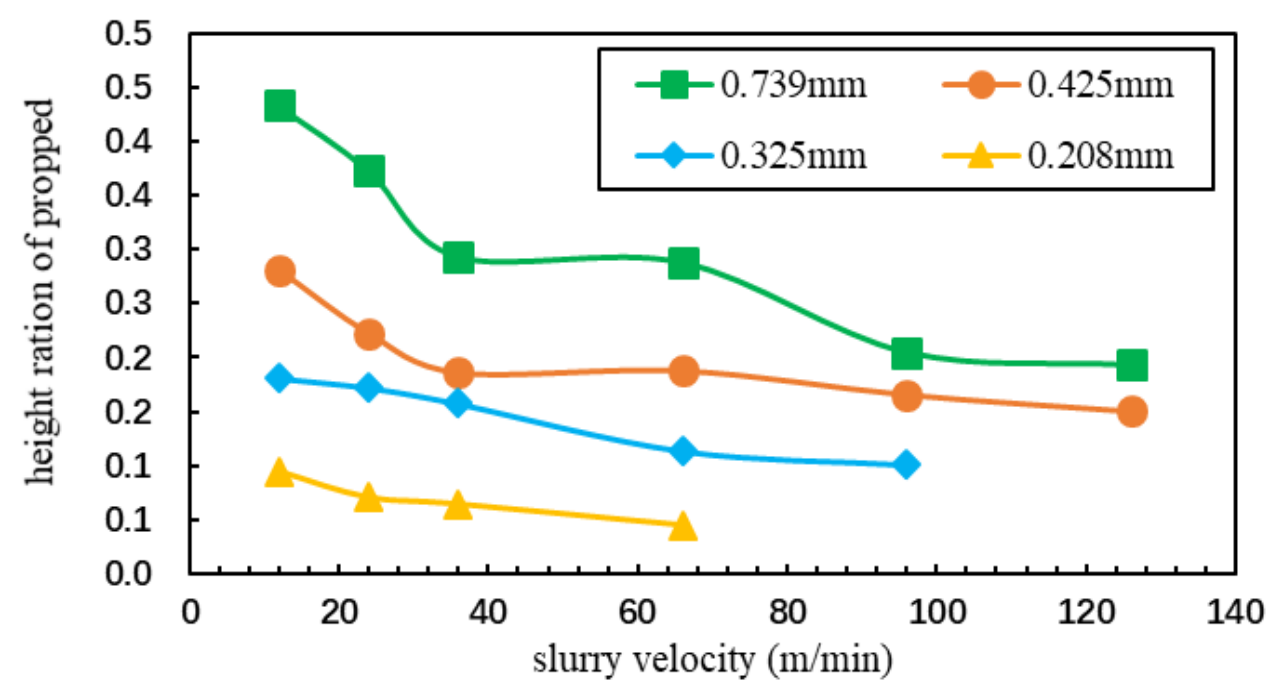

Fig.16 Changes of sand bank equilibrium height with slurry velocity and sand diameter

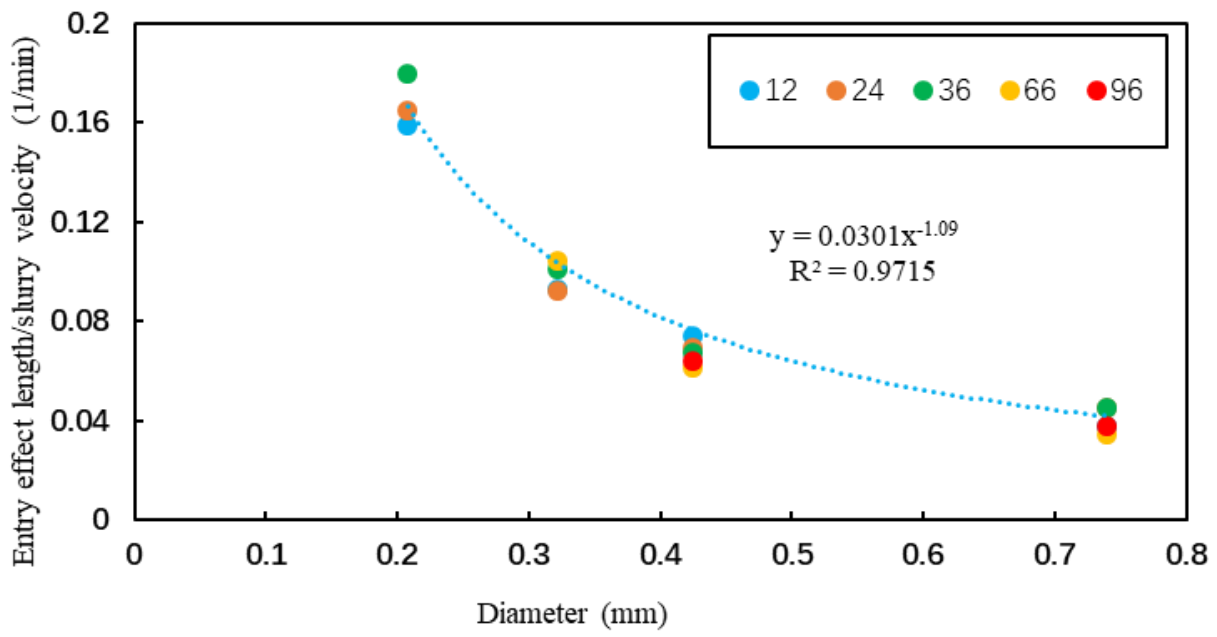

Fig.17 Settling velocity with different diameter (the legend means the slurry velocity, and the unit is $\mathrm{m} / \mathrm{min}$ ) 

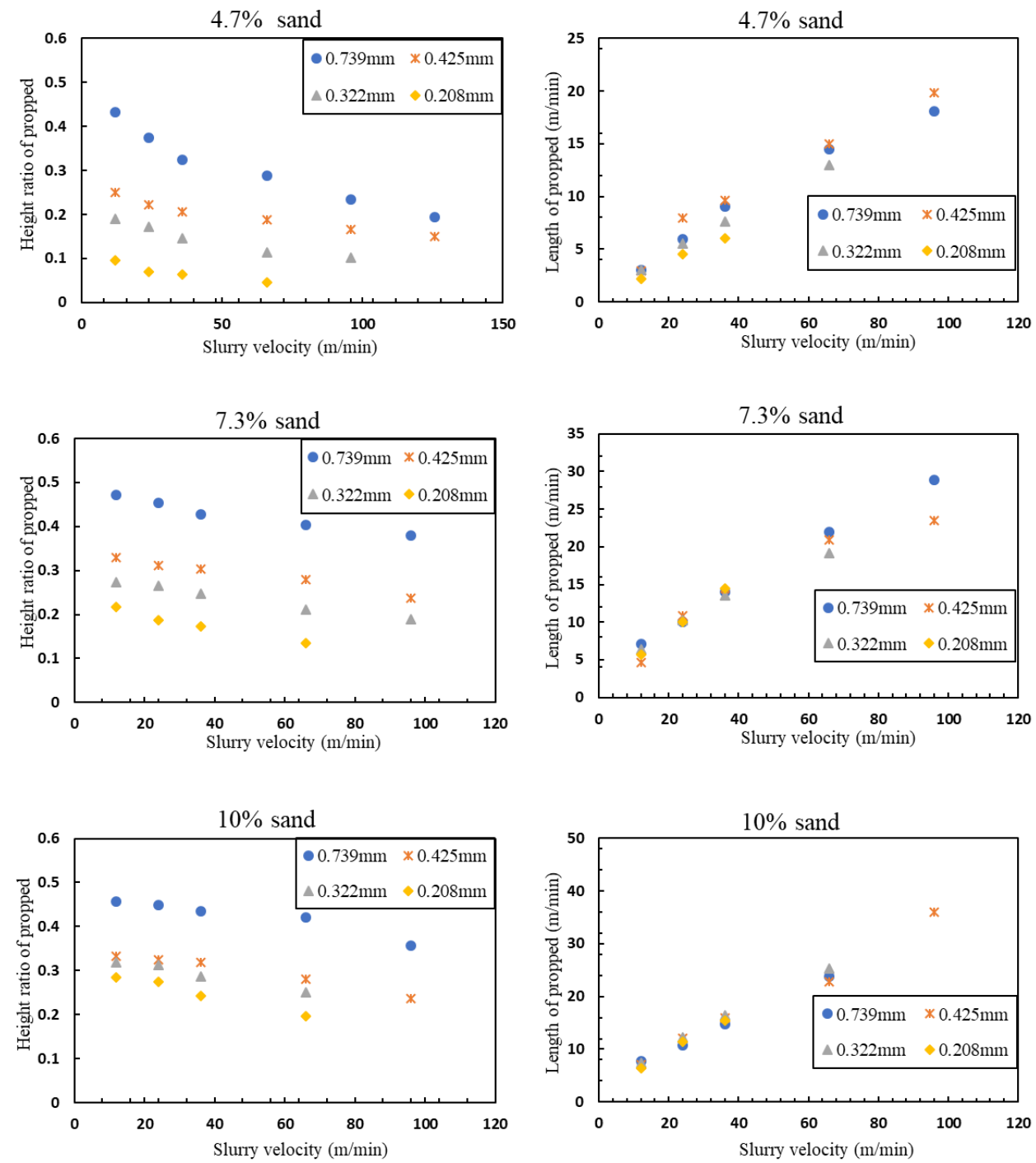

Fig.18 Changes of sand bank equilibrium height ratio (left column) and propagation rate of propped fractures (right column) with slurry velocity, sand diameter, and sand volume fraction.

\subsubsection{Effect of surface roughness}

Finally, the effect of fractures surface roughness on the transport and distribution of sand is studied. Three types of surface roughness were used for the investigation. Fig 19 shows the change of sand distribution in different cases when the Ras are 0.39, 0.59 and 0.79 . When the $\mathrm{Ra}$ is 0.39 , the equilibrium height of the sand bank is $0.130 \mathrm{~m}$ and increases to $0.152 \mathrm{~m}$ when $\mathrm{Ra}$ is 0.79 . As is shown in Fig.20, at the beginning of sand injection, the roughness has no obvious influence on the transport and distribution of the sand. With time going by, when the sand bank builds up, it can be seen that with the increase of roughness, the height of the sand bank gradually increases, and the moving 
forward rate of the sand bank in the fractures gradually decreases. It can be explained that as the roughness increases, the force between particles and the wall is further strengthened. It can be inferred that with the increase of surface roughness, the probability of particle and wall collision is higher which resulting in a gradual decrease in particle settling velocity, so the sand can be carried to the fractures by the fracturing fluid. Furthermore, as the fractures roughness increases, at the beginning of sand injection, the sand can be transported further and forms a longer sand bank. At the same time, as the roughness increases, the frictional resistance between the particles and the fractures wall will be stronger. Thus, the distance between the fractures and the height of sand bank will decrease, so that the sand transported with the fracturing fluid and the accumulation of sand bank reform a new balance. That is to say, a higher sand bank will be formed.
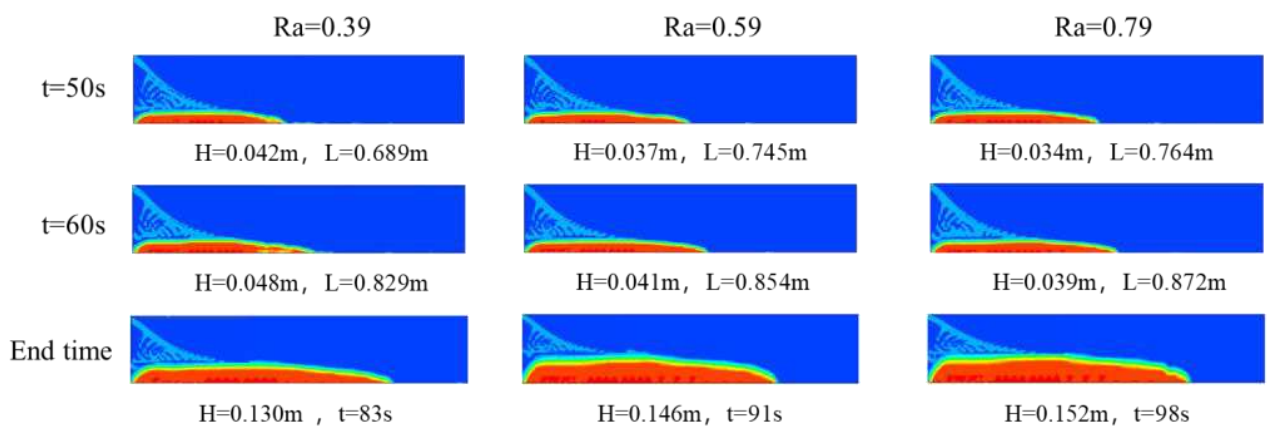

Fig.19 Changes of sand bank equilibrium height and propagation rate of propped fractures with Ra (roughness of fractures, slurry velocity $0.2 \mathrm{~m} / \mathrm{s}, 20 / 40$ mesh sand; $7.3 \%$ sand.).

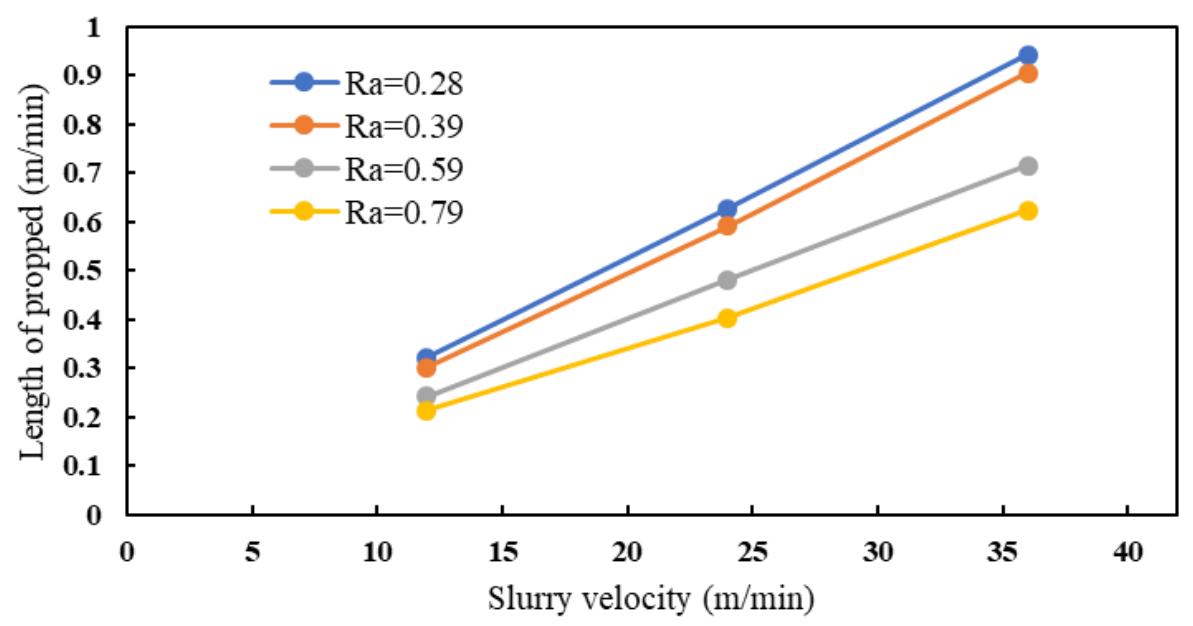

Fig.20 Comparison of propped length with different Ra 


\subsubsection{Effect of the tortuous fractures}

Next, an analysis was carried out to investigate the impact of near wellbore tortuous fractures on sand transportation and distribution. A comparation is made between straight fractures and tortuous fractures. In this model, the tortuous model is simplified as a ' $\mathrm{v}$ ' shape model at different place of the fractures. Fig. 21 shows the results of sand volume fraction contour plot of different fractures. The contour plot looks the same for the tortuous away from wellbore and straight fractures. As for the near wellbore tortuous fracture, the sand bank is significantly different. In this kind of fractures, the sand tends to form a plug and resulting the later slurry is difficult to inject.

A velocity vector plot is put forward to explain this situation. At is shown in Fig.22, at the near wellbore tortuous model, the horizontal velocity of granular phase apparently decreases. The appearance of near wellbore tortuous creates an additional resistance to sand to transport. When the sand bank gets equilibrium at the position, due to the unsteady flow conditions at the tortuous position, it is easy to produce vortices. The generation of vortices will cause the accumulated sand transported again. Thus, there is a significant height of sand bank change at the tortuous position.

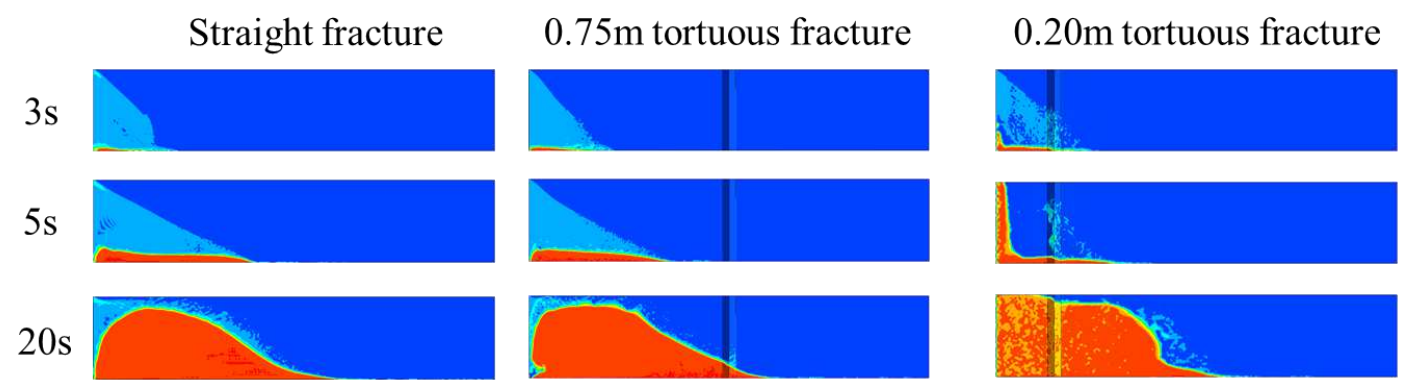

Fig.21 Sand volume fraction contour plot with different position of tortuous

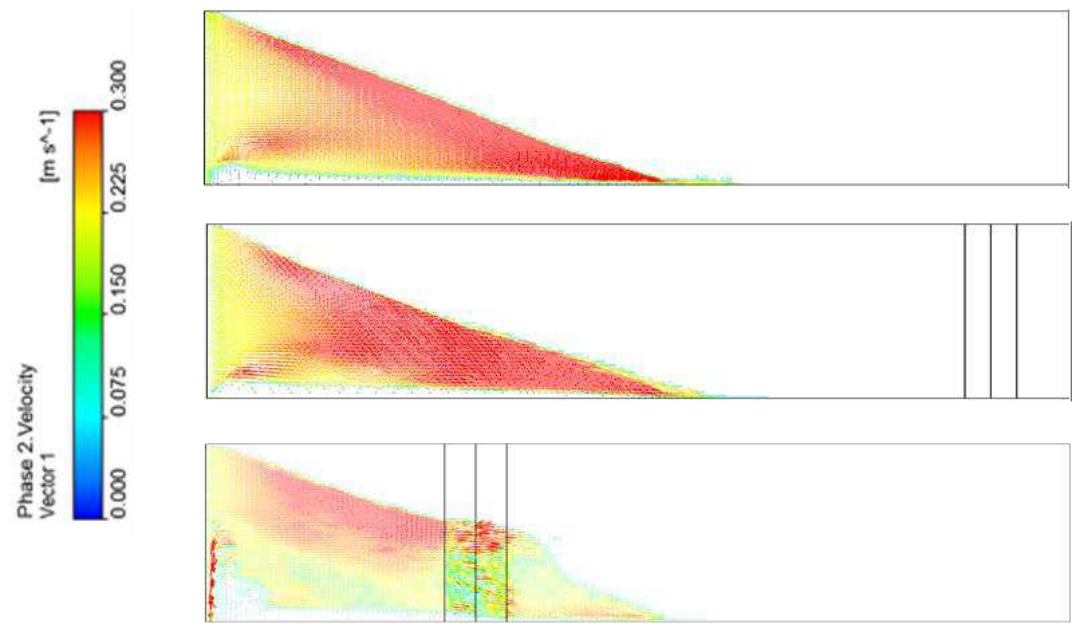

Fig.22 Velocity vector analysis in different fractures 


\section{Conclusions}

In this study, sand transport and distribution in rough and tortuous fractures is investigated using Dense Discrete Phase Model (DDPM). Surface height integral (Ra) is quantitatively used to study the effect of fracture roughness on sand movement. Three sensitive parameters were analyzed to study the key factors that influence the sand transport and distribution including injection rate, sand diameter, sand volume fraction and roughness of fractures.

Among all of the factors, slurry velocity is the most important parameter affects the sand transport and distribution. In order to reduce field working time, increasing the volume fraction of sand injection is a practical approach. Compared with smooth fractures, roughness fractures walls employ resistance during sand transport, reducing the settling velocity of sand in fractures. With the increase of Ra, sand bank equilibrium height increases and rate of propped length decrease. Based on the simulation results, an analytical solution is built which can easily predict field scale sand transport and distribution.

In tortuous fractures model, the flow phenomenon is different from in straight fractures. Due to the ' $\mathrm{v}$ ' shaped model, the slurry velocity obviously decreases and lend to the higher sand bank and slower propped length. 



\section{References}

1. Hu, X. et al. Development of a New Mathematical Model To Quantitatively Evaluate Equilibrium Height of Proppant Bed in Hydraulic Fractures for Slickwater Treatment. SPE Journal 23, 2158-2174 (2018).

2. Yao, S., Chang, C., Hai, K., Huang, H. \& Li, H. A review of experimental studies on the proppant settling in hydraulic fractures. Journal of Petroleum Science and Engineering 109211 (2021) doi:10.1016/j.petrol.2021.109211.

3. Kern, L. R., Perkins, T. K. \& Wyant, R. E. The Mechanics of Sand Movement in Fracturing. Journal of Petroleum Technology 11, 55-57 (1959).

4. Shrivastava, K. \& Sharma, M. M. Proppant Transport in Complex Fracture Networks. in (OnePetro, 2018). doi:10.2118/189895-MS.

5. Harrington, L. J., Hannah, R. R. \& Williams, D. Dynamic Experiments On Proppant Settling In Crosslinked Fracturing Fluids. in (OnePetro, 1979). doi:10.2118/8342-MS.

6. McMechan, D. E. \& Shah, S. N. Static Proppant-Settling Characteristics of Non-Newtonian Fracturing Fluids in a Large-Scale Test Model. SPE Production Engineering 6, 305-312 (1991).

7. Gadde, P. B., Liu, Y., Norman, J., Bonnecaze, R. \& Sharma, M. M. Modeling Proppant Settling in Water-Fracs. in (OnePetro, 2004). doi:10.2118/89875MS.

8. Patankar, N. A. et al. Power law correlations for sediment transport in pressure driven channel flows. International Journal of Multiphase Flow 28, 12691292 (2002). 
9. Wang, J., Joseph, D. D., Patankar, N. A., Conway, M. \& Barree, R. D. Bipower law correlations for sediment transport in pressure driven channel flows. International Journal of Multiphase Flow 29, 475-494 (2003).

10. Xu, J. et al. Numerical analysis of proppants transport in tortuous fractures of shale gas reservoirs after shear deformation. Journal of Natural Gas Science and Engineering 78, 103285 (2020).

11. Zhang, J. \& Dunn-Norman, S. Computational Fluid Dynamics (CFD) Modeling of Proppant Transport in A Plug and Perf Completion with Different Perforation Phasing. in Unconventional Resources Technology Conference (Society of Petroleum Engineers, 2015). doi:10.2118/178654-MS.

12. Huang, H., Babadagli, T., Li, H. A., Develi, K. \& Wei, G. Effect of injection parameters on proppant transport in rough vertical fractures: An experimental analysis on visual models. Journal of Petroleum Science and Engineering 180, 380395 (2019).

13. Barton, N. \& Choubey, V. The shear strength of rock joints in theory and practice. Rock Mechanics 10, 1-54 (1977).

14. Babadagli, T., Ren, X. \& Develi, K. Effects of fractal surface roughness and lithology on single and multiphase flow in a single fracture: An experimental investigation. International Journal of Multiphase Flow 68, 40-58 (2015).

15. Suri, Y., Islam, S. Z. \& Hossain, M. Effect of fracture roughness on the hydrodynamics of proppant transport in hydraulic fractures. Journal of Natural Gas Science and Engineering 80, 103401 (2020). 
16. Gale, J. F. W., Elliott, S. J. \& Laubach, S. E. Hydraulic Fractures in Core From Stimulated Reservoirs: Core Fracture Description of HFTS Slant Core, Midland Basin, West Texas. in Proceedings of the 6th Unconventional Resources Technology Conference (American Association of Petroleum Geologists, 2018). doi:10.15530/urtec-2018-2902624.

17. Maity, D. \& Ciezobka, J. An Interpretation of Proppant Transport Within the Stimulated Rock Volume at the Hydraulic-Fracturing Test Site in the Permian Basin. SPE Reservoir Evaluation \& Engineering 22, 477-491 (2019).

18. Liu, Y., Gadde, P. B. \& Sharma, M. M. Proppant Placement Using ReverseHybrid Fracs. 9 (2007).

19. Gidaspow, D., 1994. Multiphase flow and fluidization: continuum and kinetic theory descriptions. Academic Press.

20. Tong, S. \& Mohanty, K. K. Proppant transport study in fractures with intersections. Fuel 181, 463-477 (2016).

21. Gidaspow, D., Bezburuah, R., and Ding, J., 1992. Hydrodynamics of circulating fluidized beds, kinetic theory approach. In: fluidization VII, Proceedings of the 7th Engineering Foundation Conference on Fluidization, pp. 75-82.

22. Ogawa, S., Umemura, A. and Oshima, N., 1980, On the equation of fully fluidized granular materials. J. Appl. Math. Phys. 31, 483-484.

23. Schaeffer, D. G., 1987. Instability in the evolution equations describing incompressible granular flow. J. Diff. Eq. 66, 19-50.

24. Ma, D. and Ahmadi, G., 1990. A thermodynamical formulation for dispersed multiphase turbulent flows. Int. J. Multiphase Flow. 16:323-351. 
